\section{Optimization of stunning electrical parameters to improve animal welfare in a poultry slaughterhouse}

\author{
Mariagrazia Girasole, ${ }^{1}$ Claudia Chirollo, ${ }^{1}$ \\ Marina Ceruso, ${ }^{1}$ Lucia Vollano, ${ }^{1}$ \\ Antonio Chianese, ${ }^{2}$ Maria Luisa Cortesi ${ }^{1}$ \\ 'Department of Veterinary Medicine and \\ Animal Production, University of Naples \\ Federico II; ${ }^{2}$ Department of Prevention and \\ Veterinary Service of Food Hygiene, Local \\ Health Unit Napoli 2 Nord, Naples, Italy
}

\section{Abstract}

Animal killing for food production and the related operations are events that may induce pain, stress, fear and other forms of suffering to the animals. To face this problem and guarantee the animal welfare, the EU has adopted the Regulation (EC) N. 1099/2009 on the protection of animals at the time of killing. Electrical water bath stunning is one of the methods used in commercial slaughterhouses to protect poultry welfare. In particular, this method induces unconsciousness into the birds due to run of electrical current through the head and body. The aim of the present work was to find an optimal setting of electrical parameters to obtain an effective water bath stunning in a commercial poultry slaughterhouse. Moreover, the influence of the tested electrical parameters on meat quality was evaluated. All the experiments confirmed that high stunning frequencies induce a lower occurrence of lesions on carcasses but, on the other hand, require greater current intensities to be effective. A frequency of $750 \mathrm{~Hz}$ and an average current intensity of $200 \mathrm{~mA}$ for each bird in the water bath resulted as the best combination of electrical parameters to obtain a proper stunning without any consequence on the meat quality.

\section{Introduction}

Animal welfare standards are becoming increasingly important even if there are different opinions in the definition of acceptable animal welfare conditions due to cultural, ethical or religious differences between individuals. The treaty of Lisbon (European Commission, 2007) recognizes animals as sentient beings, capable of feeling pain and pleasure, so that the European Commission has adopted specific programmes to improve the animal welfare conditions and to protect them from maltreatment, abuse, pain or suffering during transport, restraint, stunning, slaughter, or killing. The World Organization for Animal Health (OIE) in its Terrestrial Animal Health Code states that the use of animals carries with it an ethical responsibility to ensure the welfare of such animals to the greatest extent practicable (0IE, 2008).

Animal killing for food production and the related operations are among the events that may induce pain, stress, fear and other forms of suffering to the animals even under the best available technical conditions. On the other hand, as widely described in literature, a better protection of animals during slaughter contributes to improving the quality of the meat.

The Directive 93/119/EC (European Commission, 1993) on the protection of animals at the time of slaughter or killing had already established common minimum rules for the protection of animals at the time of slaughter or killing in the Community. In 2009, the EU adopted the Regulation (EC) N. 1099/2009 on the protection of animals at the time of killing, which lays down rules for the killing of animals bred or kept for the production of food, wool, skin, or other products (European Commission, 2009). This Regulation establishes the killing of animals (except some derogation, e.g. the religious slaughter) only after stunning, which is necessary to induce a lack of consciousness and sensibility. In order to maintain the loss of consciousness and sensibility until the death of the animal, the stunning procedure has to be performed in accordance with specific methods and parameters. In particular, the duration of unconsciousness induced by a stunning method must be longer than lapse between the end of stun and the time to onset of death. In this sense, the efficiency of slaughter (bleeding) procedure plays a very important role.

Given the high number of broiler chickens slaughtered for human consumption [about 60 billion of birds per year (FA0, 2012)], the welfare of these animals during slaughter is of significant concern. To protect the poultry welfare, electrical water bath stunning is one of the methods used in commercial slaughterhouses. After shackling, the birds are immersed (generally up to their shoulders) into an electrified water bath, inducing unconsciousness due to the run of electric current through the head and body; the necks of the birds are then cut mechanically. Depending on the dimensions of the water bath, several birds are simultaneously treated. Conventionally, a metal strip in the base of the water bath forms the positive electrode and the shackles earthed form the negative electrode, so that the electric current passes through the bird in the direction from head to legs. In particular, when the animals touch the water, the circuit closes causing the current to run through the head
Correspondence: Mariagrazia Girasole Department of Veterinary Medicine and Animal Production, University of Naples Federico II, Via Federico Delpino 1, 80137 Naples, Italy.

Tel: +39.081.2536082 - Fax: +39.081.458683.

E-mail: mariagrazia.girasole@unina.it

Key words: Stunning; Water bath; Poultry; Animal welfare.

Conflict of interest: the authors declare no potential conflict of interest.

Received for publication: 24 February 2015.

Revision received: 28 April 2015.

Accepted for publication: 13 May 2015.

This work is licensed under a Creative Commons Attribution 3.0 License (by-nc 3.0).

(C) Copyright M. Girasole et al., 2015

Licensee PAGEPress, Italy

Italian Journal of Food Safety 2015; $4: 4576$

doi:10.4081/ijfs.2015.4576

and body. The presence of several birds at the same time in the water creates a parallel pathway of resistance.

Different combinations of electrical parameters can be chosen in order to optimize the current flow and achieve an effective, rapid, and long lasting stunning. In particular, the current intensity, the voltage, the frequency and the current type (alternating current or direct current) are the most common electrical parameters that can be changed to improve the stunning effectiveness and maintain a good meat quality. Often alternating current (AC) is used, even if in some slaughterhouses a pulsed direct current (DC) is applied. Values of frequency of $50 / 60 \mathrm{~Hz}$ up to more than $2000 \mathrm{~Hz}$ may be used. In general, higher frequencies are less effective at stunning and require greater current intensities. On the other hand, low frequencies cause high muscle contractions and consequent rupture of small blood vessels in the skin and/or flesh point. These aspects produce carcass defects with downgrading of meat quality (Wilkins et al., 1999). Therefore, to ensure both carcass and meat quality, higher stunning frequencies $(>300$ $\mathrm{Hz}$ ) have become more common in poultry slaughterhouses (Bilgili, 1999; Gazdziak, 2007). Several authors (Gregory and Wilkins, 1989; Wilkins et al., 1999; Raj at al., 2001) have reported the adverse effect of high stunning currents (especially at low frequencies) on meat quality. For instance in broilers stunned with currents higher than $130 \mathrm{~mA}$ an increase of breast muscle hemorrhages has been found. Red wing tips were also observed with a $50 \mathrm{~Hz}$ sine wave AC above $110 \mathrm{~mA}$. Use of high frequencies can reduce the occurrence of these adverse effects. Raj et al. (2001), for example, 
found a significantly lower occurrence of broken bones and breast meat hemorrhages in broilers stunned with a sine wave AC of $1500 \mathrm{~Hz}$ compared to $50 \mathrm{~Hz}$. A significant reduction of ventricular fibrillation and cardiac arrest was also observed with higher frequencies (Bilgili, 1999; Gazdziak, 2007). The Annex I of the Regulation (EC) N.1099/2009 establishes the minimum currents at which the animals shall be exposed in the water bath to guarantee an effective stunning. In particular, it defines three different current levels in correspondence of three different frequency ranges. A minimum exposure time for each bird of four seconds is also suggested. An EFSA Scientific Opinion (EFSA, 2012) specifies that the duration of unconsciousness induced by electrical stunning should be at least 45 seconds from the start of stunning to death by bleeding out.

According to the Regulation (EC) N.1099/2009, meat producers shall ensure that operators responsible for stunning carry out regular checks to ensure that the animals do not present any signs of consciousness or sensibility in the period between the end of the stunning process and death. Measuring the lack of consciousness and sensibility (i.e. ability to feel pain) of an animal is complex and it needs to be performed under scientifically approved methodology. The occurrence of a flat, isoelectric, electroencephalogram (EEG) with a profound reduction of electrical brainpower to less than $10 \%$ of the pre-stun level has been used to indicate unconsciousness in broilers (Raj et al., 2006a, 2006b; Prinz et al., 2012). However, due to physical (line speed, difficulties to observation, high number of birds slaughtered, etc.) and economic (time, costs) constraints, use of EEG to verify the animal unconsciousness is not applicable in practice in the modern commercial poultry slaughterhouses. Indications about the effectiveness of stunning can also be obtained under the field conditions. Changes in the behavior of poultry (e.g. spontaneous blinking, wing flapping, spontaneous swallowing, head shaking), physical signs (e.g. onset of seizures, cessation of breathing, fixed eye) and physiological reflexes (e.g. response to external stimulus such as corneal reflex, response to pain stimulus such as comb or toe pinching) represent the common parameters used by the operators (Erasmus et al., 2010; Prinz et al., 2012).

Among physical reflexes, the corneal reflex seems to be the most reliable parameter to evaluate unconsciousness (Prinz et al., 2010; Erasmus et al., 2010; EFSA, 2013). In particular, the absence of corneal reflex in broiler chickens is considered as an effective indicator of deep unconsciousness (Gregory and Wilkins, 1989). A positive response itself, however, does not necessarily indicate sensitivity in broilers and ability to perceive pain; for this reason, it can be expected that a limited number of animals might still show a positive response for a short period post-stun. Under practical field conditions a maximum of $30 \%$ of corneal reflexes can be used as an indicator to identify an acceptable stunning. Studies based on the comparison between EEG results and occurrence of corneal reflex confirm this assumption (Prinz et al., 2010,2012). The aim of the present work is to identify the optimal setting of electrical parameters to obtain an effective water bath stunning in a commercial poultry slaughterhouse. In particular, different combinations of voltage and frequency values were tested in order to achieve a satisfying unconsciousness of the animals until their death. Moreover, the influence of the tested electrical parameters on broilers meat quality was evaluated.

\section{Materials and Methods}

A local commercial poultry slaughterhouse equipped with electrical water bath for bird stunning has been selected. A commercial stunner (LINCO ${ }^{\circledR}$ Water Stunner BA4) was used to modify the voltage and frequency levels of the electric current provided to the water bath. The slaughter line speed was set up to ensure for each bird a minimum stunning time of $4 \mathrm{~s}$, with four birds simultaneously submerged in the water. A digital ammeter placed on the water bath equipment allowed the monitoring of the actual total current in the water bath. As the birds present at the same time in the water creates a parallel pathway of resistance, calculations for the average current passing through the individual birds were made based on the measured amount at the water bath divided by the number of birds (four) simultaneously submerged in the water. Three different frequency levels $(200 \mathrm{~Hz}, 600 \mathrm{~Hz}$ and $750 \mathrm{~Hz}$ ) combined with different voltages were tested. The selected electrical parameters allowed average currents passing through each chicken compliant with those required in the Annex $I$ of the Regulation (EC) N.1099/2009 (European Commission, 2009). The state of consciousness, as result of an ineffective or poor stun of the birds, was evaluated at three key stages: i) immediately after stunning, ii) at the time of neck cutting, and iii) during bleeding until death occurred. The parameter used as consciousness indicator was a positive corneal reflex (blinking response elicited by touching or tapping the cornea) and the stunning process was considered as inadequate if it induced a positive corneal reflex in more than $30 \%$ of birds. The effects of each tested combination of stunning electrical parameters were evaluated on 100 consecutive broiler chickens (genetic line Ross 708) having weights ranging from 3 to $4.5 \mathrm{~kg}$. Moreover, the carcasses and meat quality parameters in relation to the above stunning conditions parameters were evaluated. To this aim, a visual inspection on the carcasses after chilling was performed.

\section{Results}

In Table 1 the results obtained with different stunning procedures (different combinations

Table 1. Effect of different electrical stunning procedures on the percentage of broilers with corneal reflex and the occurrence of gross lesions on carcasses.

\begin{tabular}{|c|c|c|c|c|c|c|}
\hline Frequency $(\mathrm{Hz})$ & $\begin{array}{l}\text { Voltage } \\
\text { (V) }\end{array}$ & $\begin{array}{l}\text { Average live } \\
\text { weight } \\
\text { (kg) }\end{array}$ & $\begin{array}{l}\text { Total } \\
\text { current } \\
\text { (A) }\end{array}$ & $\begin{array}{l}\text { Estimated } \\
\text { current/bird } \\
\text { (mA) }\end{array}$ & $\begin{array}{l}\text { Percentage of animals } \\
\text { with corneal reflex } \\
\text { (\%) and standard error (\%) }\end{array}$ & $\begin{array}{l}\text { Number of } \\
\text { carcasses with } \\
\text { gross lesions }\end{array}$ \\
\hline 200 & 40 & 3.95 & 0.12 & 30 & $92(2.71)$ & - \\
\hline 200 & 80 & 3.75 & 0.21 & 53 & $25(4.33)$ & $\begin{array}{c}29 \text { carcasses with petechiae } \\
\text { and blood effusions } \\
\text { on breasts and legs }\end{array}$ \\
\hline 200 & 100 & 3.75 & 0.26 & 66 & $5(2.18)$ & $\begin{array}{l}67 \text { carcasses with petechiae } \\
\text { and blood effusions } \\
\text { on breasts and legs }\end{array}$ \\
\hline 600 & 160 & 4.2 & 0.60 & 150 & $46(4.98)$ & - \\
\hline 750 & 220 & 4.2 & 0.80 & 200 & $12(3.25)$ & - \\
\hline
\end{tabular}


between frequency and voltage of electrical current) on broilers slaughtered at different live weight are summarized. A frequency of $200 \mathrm{~Hz}$ and a voltage of $40 \mathrm{~V}$ were initially set for broilers with an average live weight of 3.95 $\mathrm{Kg}$. These values generated a total current of $120 \mathrm{~mA}$, as displayed on the ammeter at the water bath. So, the estimated average current flowing through each bird was $30 \mathrm{~mA}$ (120 mA divided by the number of birds simultaneously submerged in the water). These stunning parameters induced in $92 \%$ of the tested broiler chickens, with a standard error (SE) of $2.71 \%$, a positive response to the corneal reflex

In order to improve the stunning effectiveness and to reduce the number of animals with a positive corneal reflex, the applied voltage was increased. In particular, two different voltages $(80 \mathrm{~V}$ and $100 \mathrm{~V})$ were tested for broilers with an average live weight of $3.750 \mathrm{Kg}$. These combinations generated total average electric currents in the water bath of $210 \mathrm{~mA}$ and 260 $\mathrm{mA}$, respectively corresponding to estimated average currents per individual bird of $53 \mathrm{~mA}$ (at $80 \mathrm{~V}$ ) and $66 \mathrm{~mA}$ (at $100 \mathrm{~V}$ ).

Stunning with an estimated current of 53 $\mathrm{mA}$ showed a positive response to the corneal reflex in $25 \%$ of the animals (with a SE of $4.33 \%$ ). A significant reduction of birds with corneal reflex (only 5\%) was observed when an estimated current of $66 \mathrm{~mA}$ per animal was applied.

About one third (29\%) of the birds stunned with a current of $53 \mathrm{~mA}$ showed lesions mainly in breast but also in leg muscles. Petechiae and wide blood effusions (Figures 1, 2 and 3) represented the most frequent lesions. A higher percentage of animals (67\%) with similar lesions was found in the birds stunned with a current of $66 \mathrm{~mA}$.

As a consequence of the above results, the effects of higher frequency currents, in particular frequencies of 600 and $750 \mathrm{~Hz}$, were investigated. An average estimated current for each bird of $150 \mathrm{~mA}$ at $600 \mathrm{~Hz}$ and $200 \mathrm{~mA}$ at $750 \mathrm{~Hz}$ were applied to 100 birds having an average live weigh of $4.2 \mathrm{Kg}$. The corneal reflex was still used as consciousness indicator but, in order to have additional information on stunning effectiveness, the response to comb pinch was also evaluated. The obtained results showed that when birds were stunned with an estimated current of $150 \mathrm{~mA}$ and a frequency of $600 \mathrm{~Hz}, 46 \%$ of animals was positive to the corneal reflex (with a SE of 4.98\%) and no one of them was positive to comb pinching test. Stunning with an average electric current for individual bird of $200 \mathrm{~mA}$ at a frequency of 750 $\mathrm{Hz}$ produced a lower percentage (12\%) of animals with a positive response to corneal reflex and no positive birds to comb pinching test. No negative effect has been found on carcasses and meats as well as no macroscopic lesions in both experiments.

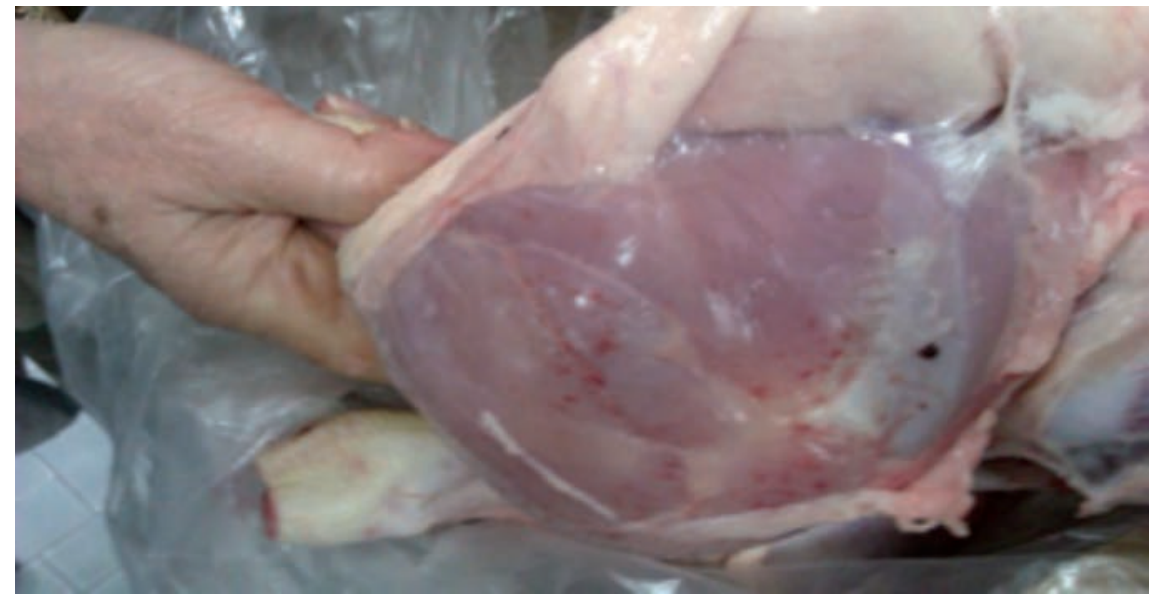

Figure 1. Petechiae on a chicken carcass after stunning at $200 \mathrm{~Hz}$ and $53 \mathrm{~mA}$.

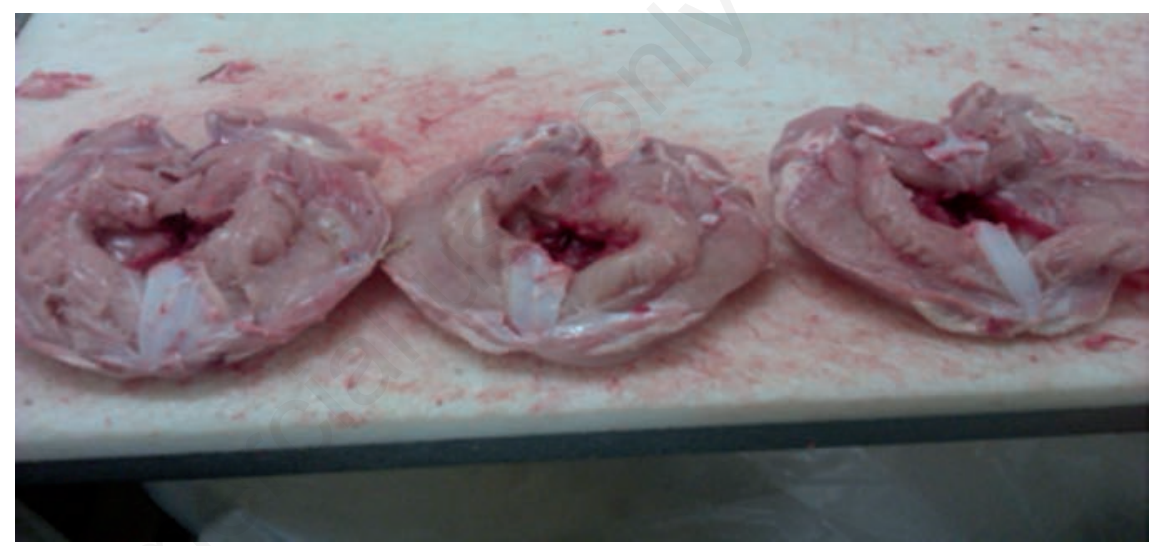

Figure 2. Petechiae and wide blood effusions after stunning at $200 \mathrm{~Hz}$ and $66 \mathrm{~mA}$.

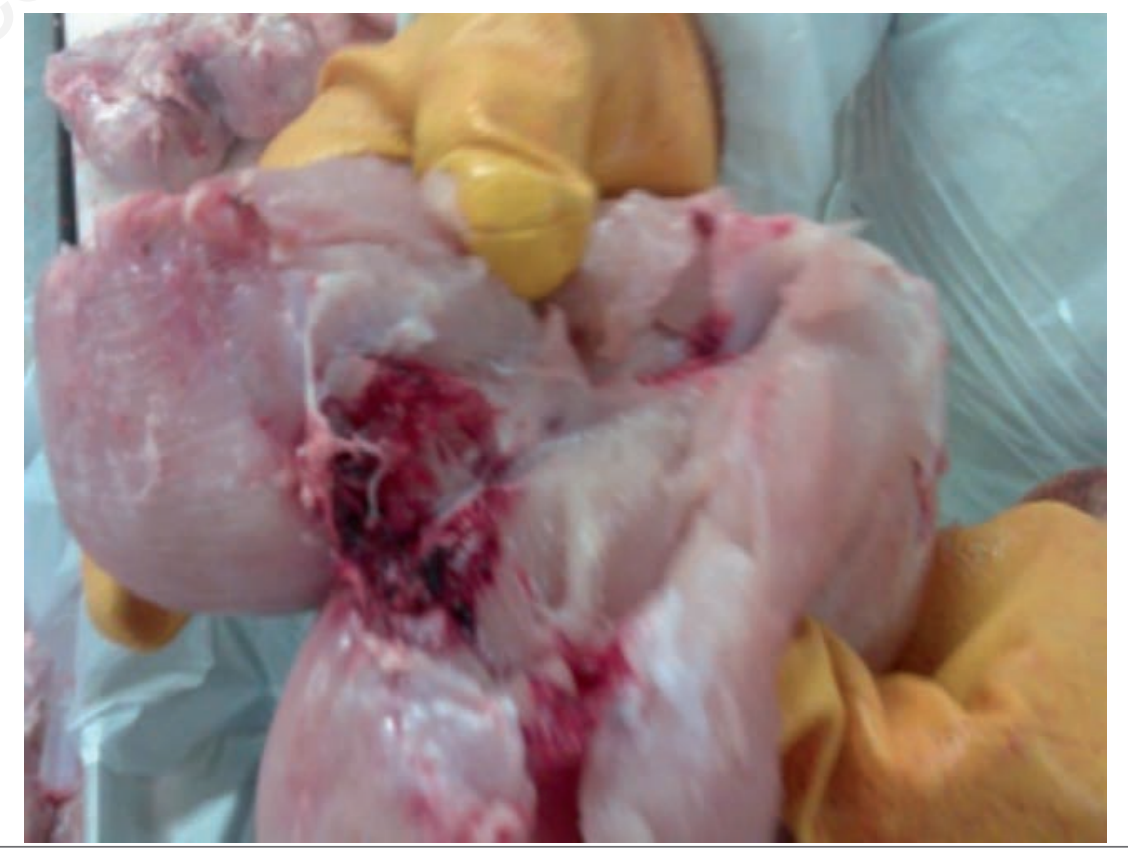

Figure 3. Petechiae and blood effusion on leg muscles after stunning at $200 \mathrm{~Hz}$ and $66 \mathrm{~mA}$. 
The above reported results indicated that a frequency of $750 \mathrm{~Hz}$ and a total current of 800 $\mathrm{mA}$ (200 mA per bird) could guarantee an effective stunning for the majority of the broilers without compromising the carcass and meat quality.

\section{Discussion}

Our experiments confirmed that high stunning frequencies induce a lower occurrence of lesions on carcasses, but are less effective at stunning and require greater electrical current intensities to be effective. The results also suggested that electrical water bath stunning, complying with the parameters indicated in the Regulation (EC) N. 1099/2009, rarely produces unconsciousness in all the animals without any consequence on meat quality.

A reason for this result is that both in the Annex I to Regulation (EC) No 1099/2009 and in the stunning equipment at the slaughterhouses, the optimal electrical parameters are defined as an average value per animal. The electrical current measured (and that can be read on the ammeter at the abattoir) in a multiple-bird stunning water bath indicates the total current that flows through all the birds in the water bath, and can be used to calculate only the average current for each bird (Sparrey et al., 1993). As variations in impedance (resistance) between the birds are significant, it is not possible to ensure constant electric current for each stunned chicken. Therefore, by using an average value, the risk is that some animals are not stunned effectively because they receive insufficient electric current to ensure unconsciousness and insensibility (Bilgili, 1999; Kettlewell and Hallworth, 1990; Shields and Raj, 2010). The problem could be resolved by increasing the average stunning currents in the recommendations of the Regulation (CE) N.1099/2009 (European Commission, 2009), but this can produce in some animals a poor meat quality with lesions on carcasses and meats.

The higher electrical resistivity of some animals can have several reasons. It can be due to a higher weight and/or size of these birds, to the fat content of their muscles, to a peculiar skull bone structure and thickness, but also to shackle conditions (degree of fouling, contact area with bird) (Bilgili, 1992; Boyd, 1994; Kettlewell and Hallworth, 1990). This is also the reason because most studies on electrical parameters for water-bath stunning (especially laboratory-scale studies) are difficult to extrapolate directly to large-scale field conditions (Bilgili, 1999; Raj, 2004). Further research would be needed to ensure that also birds with an higher impedance are stunned effectively avoiding, at the same time, lesions on carcasses of broiler chickens with lower resistance to the electrical current flowing. For this reason, the influence of some peculiar features of broilers on their electrical resistivity is currently investigated.

\section{Conclusions}

The present work aimed to find an optimal setting of electrical parameters for the water bath stunning in a commercial poultry slaughterhouse without any negative influence on carcass and meat. The results obtained, using several combinations of voltages and frequencies, showed that low frequencies $(200 \mathrm{~Hz})$ were not able to guarantee adequate welfare conditions with low electric current intensity (30 mA/bird). An increase in electric current intensity (53 and $66 \mathrm{~mA}$ /bird), maintaining a frequency of $200 \mathrm{~Hz}$, produced macroscopic lesions on carcasses with an adverse effect on meat. On the contrary, a frequency of $750 \mathrm{~Hz}$ and an intensity of $200 \mathrm{~mA}$ for each bird resulted as the best combination of electrical parameters to obtain an effective stunning for the majority of animals without negative impact on the carcass and meat quality.

\section{References}

Bilgili SF, 1992. Electrical stunning of broilers. Basic concepts and carcass quality implications: a review. J Appl Poultry Res 1:135-46.

Bilgili SF, 1999. Recent advances in electrical stunning. Poultry Sci 78:282-6.

Boyd F, 1994. Humane slaughter of poultry: the case against the use of electrical stunning devices. J Agr Environ Ethic 7:221-36.

EFSA, 2012. Scientific opinion on the electrical requirements for water bath stunning equipment applicable for poultry. EFSA J 10:2757.

EFSA, 2013. Scientific opinion on monitoring procedures at slaughterhouses for poultry. EFSA J 11:3521.

Erasmus MA, Turner PV, Widowski TM, 2010. Measures of insensibility used to determine effective stunning and killing of poultry. J Appl Poultry Res 19:288-98.

European Commission, 1993. Council directive on the protection of animals at the time of slaughter or killing, 93/119/EC. In: Official Journal, L 340, 22.12.1993.

European Commission, 2007. Treaty of Lisbon amending the Treaty on European Union and the Treaty establishing the European Community, signed at Lisbon, 13 December 2007, 2007/C 306/01. In: Official Journal, C306:49, 17.12.2007.

European Commission, 2009. Council Regulation of 24 September 2009 on the protection of animals at the time of killing, 1099/2009/EC. In: Official Journal, L303, 18.11.2009.

FA0, 2012. Available from: http://faostat. fao.org/site/569/DesktopDefault.aspx?PageID $=569 \#$ ancor

Gazdziak S, 2007. Kill floor improvements: automation on the poultry kill and eviscerating lines is increasing efficiency and product quality. Nat Prov 12:66-8.

Gregory NG, Wilkins LJ, 1989. Effect of stunning current on carcass quality in chickens. Vet Rec 124:530-2.

Kettlewell PJ, Hallworth RN, 1990. Electrical stunning of chickens. J Agr Eng Res 47:139-51.

OIE, 2007. Terrestrial animal health code 2007. Guidelines for the slaughter of animals. World Organization for Animal Health, Paris, France.

Prinz S, Van Oijen G, Ehinger F, Bessei W, Coenen A, 2012. Electrical water bath stunning: Influence of different waveform and voltage settings on the induction of unconsciousness and death in male and female broiler chickens. Poultry Sci 91:998-1008.

Prinz S, Van Oijen G, Ehinger F, Coenen A, Bessei W, 2010. Electroencephalograms and physical reflexes of broilers after electrical water bath stunning using an alternating current. Poultry Sci 89:1265-74.

Raj, ABM (2004). Stunning and slaughter of poultry. In Mead G, ed. Poultry meat processing and quality. Woodhead Publishing, Cambridge, UK, pp 65-89.

Raj ABM, Wilkins LJ, O'Callaghan M, Phillips AJ, 2001. Effect of electrical stun/kill method, interval between killing and neck cutting and blood vessels cut on blood loss and meat quality in broilers. Brit Poultry Sci 42:51-6.

Raj ABM, O`Callaghan M, Hughes SI, 2006a. The effect of amount and frequency of pulsed direct current used in water bath stunning and neck cutting methods on spontaneous electroencephalograms in broilers. Anim Welfare 15:19-24.

Raj ABM, O`Callaghan M, Knowles TG, 2006b. The effect of amount and frequency of alternating current used in water bath stunning and neck cutting methods on spontaneous electroencephalograms in broilers. Anim Welfare 15:7-18.

Shields SJ, Raj ABM, 2010. A critical review of electrical water-bath stun systems for poultry slaughter and recent developments in alternative technologies. J Appl Anim Welf Sci 13:281-99.

Sparrey JM, Kettlewell PJ, Paice MER, Whetlor WC, 1993. Development of a constant current water bath stunner for poultry processing. $\mathrm{J}$ Agr Eng Res 56:267-74.

Wilkins LJ, Wotton SB, Parkman ID, Kettlewell PJ, Griffiths P, 1999. Constant current stunning effects on bird welfare and carcass quality. J Appl Poultry Res 8:465-71. 